\title{
Relecturas de género a teorías clásicas sobre la ciencia, el poder y la política
}

\author{
Rebeca Dolores Centeno Orozco*
}

Recibido: noviembre de 2013 / Aceptado: marzo de 2014

El artículo presenta una revisión de teorías clásicas sobre epistemología, política y economía, que fueron producidas cuatro siglos antes de Cristo y en el período de la Ilustración, y que han sido utilizadas para justificar la desigualdad que experimentan las mujeres en estos campos. El paradigma de género, como teoría crítica, identifica y denuncia el sesgo androcéntrico de las ciencias para explicar cómo se reproducen las desigualdades de género en las estructuras sociales, a fin de contribuir a que a todos los seres humanos se les garantice la igualdad efectiva.

Palabras clave: construcción social de género / poder / política / androcentrismo

\section{Introducción}

"La mujer es un animal de cabellos largos e ideas cortas", señalaba Aristóteles cuatro siglos antes de Cristo. Este filósofo, junto a Sócrates y Platón, se considera fundador de los principios de la filosofía occidental. Tiempo después, las ideas de contractualitas como Locke y Rosseau definieron la noción de la democracia moderna y sus instituciones. Los planteamientos de estos filósofos crearon las bases teóricas sobre el poder y la política, las cuales se caracterizan por ser androcéntricas. Es decir, emitieron discursos desde su posición de poder para excluir "lo femenino" de los espacios considerados valiosos socialmente, como son la ciencia, la política, el poder y la economía.

\footnotetext{
* Programa Interdisciplinario de Estudios de Género (PIEG) de la Universidad Centroamericana (UCA), Managua. Consultora independiente sobre género y desarrollo. Correo electrónico: rcenteno3@yahoo.com. mx, centeno.rebeca@gmail.com
} 
Si hacemos una lectura pormenorizada de los planteamientos de las teorías clásicas, es posible identificar, sin mucho esfuerzo, la manera en que se ha construido un discurso que califica a las mujeres como deficitarias porque se ha fundado mediante el paradigma masculino. Se ha construido estructuras de desigualdad particularmente en el ámbito jurídico, económico y político que alejan a las mujeres de la ciudadanía plena, del disfrute de sus derechos humanos.

El género como construcción social, edificado a partir de la diferencia sexual, actúa a modo de sistema de estratificación que se expresa en la menor participación de las mujeres con respecto a los hombres en puestos claves donde se ostenta el poder y donde se produce conocimiento llamado científico.

\section{Pensamientos de filósofos post-socráticos: bases del orden androcéntrico del discurso académico}

Desde posiciones de poder se ha utilizado discursos que apelan a la naturaleza para justificar estratificaciones sociales, injusticia y desigualdad. Ha funcionado una especie de taxonomía social que clasifica a los seres humanos como superiores e inferiores, negando a estos últimos el derecho al desarrollo. Justamente para que se reproduzca un sistema de dominación como el Patriarcado, se debió de tener un sólido discurso que pudiera mantenerlo y reproducirlo desde hace más de 7,000 años.

La teoría feminista se funda precisamente en la noción de género como construcción social y aleja de la naturaleza la causa de la opresión de las mujeres. Argumenta que el poder patriarcal es construido socialmente y se ancla en diversas instituciones, como la familia, el Estado y el mercado. Virginia Maquieira (2001) manifiesta que cuando se constata la presencia mayoritaria de los varones en la guerra y, por el contrario, la dedicación de las mujeres a las tareas de cuidado y de crianza, surgen distintas interrogantes: ¿Hasta qué punto existen diferencias biológicas que sean responsables de la distinta distribución de papeles sociales y responsabilidades entre mujeres y varones? ¿Existe una base biológica para la división sexual de las tareas y finalmente para la subordinación de las mujeres?

Explica Maquieira (2001) que estas preguntas han sido preocupaciones constantes en la historia del pensamiento occidental. Aristóteles apeló a la naturaleza para justificar el destino no solo de las mujeres y de los varones, sino también de los varones libres y los esclavos. En "La Política", Aristóteles defiende que desde su nacimiento unos seres están destinados a regir y otros a ser regidos. Entre éstos, los que nacen para obedecer son los esclavos, las mujeres y los animales, porque la naturaleza los ha hecho inferiores. Desde la perspectiva feminista, Aristóteles ha sido un impulsor del determinismo biológico que ha llegado hasta nuestros días bajo diversos ropajes teóricos (Durán, 1999). En términos generales se entiende por determinismo biológico aquella corriente de pensamiento que explica la subalternidad de las mujeres por causas biológicas.

Así también, la teoría antropológica del siglo XX ha sido objeto de crítica feminista porque ha contribuido considerablemente a la elaboración de un discurso 
Explica Moreno Sardá (1988) que la palabra griega aner, andros, y la latina vir, viri, se refieren justamente no a cualquier hombre de cualquier edad y condición, sino al hombre hecho, es decir, a aquel que ha asimilado los valores propios de la virilidad y, en consecuencia, se cree con derecho a imponerse sobre otras y otros mujeres y hombres. Por tanto, cabe hablar del orden androcéntrico del discurso académico, orden que repercute en otros discursos públicos.

\section{Las raíces del discurso androcéntrico: la visión del poder y la política en el pensamiento de Aristóteles}

Aristóteles escribe en "La Política" (1981) que para hacer grandes cosas, es preciso ser tan superior a sus semejantes como lo es el hombre a la mujer, el padre a los hijos, el señor a los esclavos. Argumenta Moreno Sardá (1988) que en "La Política" de Aristóteles, detenerse en las palabras clave e incluso en las traducciones habituales, permite detectar cómo el filósofo griego construyó el concepto de lo humano como un arquetipo viril a la vez racista y clasista, adulto y sexista, al que definió como natural y superior.

La revisión de la literatura indica que las posibles ubicaciones sociales de las mujeres en la Grecia clásica eran: esposas, concubinas, heteras y prostitutas; se trata de una posición de subalternidad determinada exclusivamente por la relación que las mujeres establecían con los hombres. Su condición social es casi inexistente y regulada por una sociedad que la ubicaba en total subordinación a los hombres. Esta ubicación contextual (siglos antes de Cristo) no es nada disímil a lo que ocurre con las mujeres en la época llamada de postmodernidad en la que vivimos, si retomamos el título de la obra de Marcela Lagarde (1997): "Los cautiverios de las mujeres: madresposas, monjas, putas, presas y locas”. Menciona Lagarde que en el Patriarcado las mujeres experimentan diversos cautiverios porque están sujetas a un dominio masculino institucionalizado y estructurado en las relaciones sociales.

Por su parte, Cavana (2000) menciona que en las teorías antropológicas de la edad antigua, de la Patrística y la Escolástica, se considera al varón como prototipo de ser humano completo y perfecto, de tal modo que ser mujer, con la diferencia que conlleva del ser varón, es considerado indefectiblemente como un modo de ser incompleto y deficiente. Este punto de vista androcéntrico implica, pues, que la diferencia sexual es entendida necesariamente como una desigualdad de valores, y que todo lo propio de las mujeres sea interpretado como falta de ser. Como consecuencia de esta perspectiva androcéntrica se han dado en el curso de la historia una y otra vez teorías que no incluyen a la mujer dentro de la especie humana. La determinación de la mujer como inferior al hombre en cuerpo, alma y espíritu constituye una constante en la historia de la antropología androcéntrica.

Para Cavana (2000), el autor que ha sido decisivo dentro de la concepción negativa de la diferencia de sexos es Aristóteles. Según este filósofo, la diferencia de sexos proviene de la diferente participación en la reproducción y de su distinta forma: ambos sexos son origen de la misma reproducción, lo masculino engendra en lo otro, mientras que lo femenino engendra en sí mismo. Aristóteles parece desconocer los ovarios cuando afirma que el útero es lo equivalente a los testículos y al miembro masculino, y la sangre menstrual y el semen son la materia de la generación. La 
Por otro lado, Moreno Sardá (1988) traduce la palabra Polis como ciudadestado por considerar que esta expresión es la que nos proporcionan las referencias más completas de lo que era la Polis griega: una ciudad -o ciudadela- desde la que se expande una hegemonía estatal. Agrega la autora que conviene recordar la definición que Aristóteles hace de Polis en el libro III: Polis Koinonia Ton Eleutheron Estin (1279). Según esto -se interroga-, la Polis sería la asociación de los que son libres. ¿Quiere esto decir que, en sentido estricto, la Polis es la comunidad de los varones adultos griegos que ejercen el poder, y que, en consecuencia, este término sólo afecta por extensión a las restantes mujeres y hombres que habitan en el territorio controlado por los miembros de este colectivo viril?

Menciona Moreno Sardá (1988) que en el seno de la Oikia se establecen distintos tipos de relaciones que aluden al patrimonio como base de toda la economía, doméstica y pública, en la Grecia antigua y éstas son: la relación Despotike, entre el señor y los esclavos; la relación Patrike, entre padre e hijos; y la relación Gamike, entre el varón y la mujer; relaciones todas ellas de entre quien manda (Arkhos) y quienes son mandados o mandadas (Arkhomenos); y una cuarta relación que se refiere a la propiedad de los bienes que el varón adulto griego tiene derecho a disfrutar.

A pesar de ello, explica la autora que el término Oikia se refiere al patrimonio de la economía doméstica y pública, pero los estudiosos actuales centran su atención en aquellos aspectos del análisis económico de Aristóteles que hoy corresponden a la administración y explotación de los recursos humanos y naturales en el ámbito público y valorados monetariamente, y eluden prestar igual atención a aquellos que constituyen los elementos básicos de la economía doméstica o sistema patrimonial y que hoy continúan ubicados en el ámbito privado, como son las relaciones entre esposo y esposa, y las paterno-filiales, así como las bases patrimoniales de la actividad económica pública.

Justamente la división de las esferas pública y privada ha sido discusión fundante del pensamiento feminista y uno de los debates más candentes en las Ciencias Sociales. Desde las Ciencias Sociales se muestra al ámbito público separado del ámbito privado en donde -en relación jerárquica- el primero tiene mayor valor social porque está sujeto a relaciones mercantiles y posee valor de cambio. Por el contrario, el ámbito privado o doméstico ha sido conceptualizado como proveniente de un orden natural no sujeto a relaciones de mercado, impera un valor de uso y no está sujeto a leyes sociales porque es el mundo gobernado por el patter familia. Particularmente desde la economía feminista se ha desarrollado importantes teorías que argumentan que no existe tal separación de ámbitos, que existe una relación entre ambas esferas, que se han mostrado -desde la perspectiva androcéntricacomo separadas y jerarquizadas.

\section{La separación de las esferas doméstica y pública: implicaciones políticas}

Según la politóloga Carole Pateman (1996), la dicotomía entre lo privado y lo público ocupa un papel central en los casi dos siglos de textos y de lucha política feminista. En realidad, a su juicio, de esta dicotomía es de lo que trata fundamentalmente el 
y los primeros movimientos de mujeres en lucha, dispuestas a cambiar su situación, se organizan bajo las banderas de la Revolución francesa". Existe abundante literatura que versa sobre el Feminismo y la Ilustración, en la que podemos estudiar cómo las mujeres se ven relegadas del Contrato Social, con las consecuencias negativas para ejercer sus derechos a ser ciudadanas plenas.

Rosa Cobo Bedia (1995), en particular, explica cómo las mujeres fueron excluidas del contrato social. Analiza las teorías de Hobbes, Locke y Rousseau e indica que los tres reflexionaron ampliamente sobre las relaciones entre los sexos y sobre el matrimonio. Sin embargo, los tres excluyeron a las mujeres de la vida pública. Desde la perspectiva de esta catedrática feminista, en las obras de estos autores debe buscarse los orígenes del patriarcado contemporáneo y de la exclusión de las mujeres de la democracia. Argumenta Cobo Bedia (1995) que Hobbes, Locke y Rousseau, como defensores de la idea moderna de que todos nacemos libres e iguales, no podían excluir a las mujeres de esos conceptos políticos sin justificarlo adecuadamente. Por ello la legitimación la explicaron por medio de la ontología. Es decir, decidieron que la constitución de la naturaleza femenina colocaba a las mujeres en una posición de subordinación en todas las relaciones sociales en que participaban.

Una exclusión tan radical de esa nueva distribución del poder no podía realizarse por parte de quienes más activamente han defendido la igualdad natural de los individuos sin que se produzcan quiebres analíticos en sus teorías. Los tres autores participan de un rasgo común: niegan a las mujeres los derechos que se derivan de la libertad y la igualdad. Los tres conceptualizan al varón como un ciudadano -con más o menos limitaciones- y a la mujer como una súbdita. Sus universales propuestas de libertad e igualdad dejan de ser universales cuando han de ser aplicadas a las mujeres.

Una de las instituciones que reproducen tal forma de desigualdad es la familia. Explica Cobo Bedia (1995) que para Hobbes, Locke y Rousseau, la familia es la institución en la que las mujeres se ocupan de la reproducción y las mujeres son cuerpos. En Hobbes, esos cuerpos femeninos darán a luz guerreros que serán socializados para convertirse en sujetos obedientes al Estado. En Locke, sin embargo, los cuerpos de las mujeres serán utilizados para la transmisión segura de la propiedad privada por medio de los hijos consanguíneos. Estos hijos serán educados por sus madres como ciudadanos con capacidad económica. En Rousseau (1980), las mujeres darán a luz y formarán a ciudadanos libres y autónomos.

\section{La exclusión de la ciencia y del conocimiento}

La utilidad de la teoría de género radica en que sus categorías analíticas, que le son propias, han sido de gran valor para el análisis de las desigualdades que experimentan las mujeres y otros grupos de personas excluidas. Justamente una de las desigualdades más evidentes es la histórica exclusión de las mujeres de la ciencia y la academia como espacio de producción de saberes legitimados y considerados científicos, así como las dificultades de las mujeres para desempeñarse en estos campos, considerados como propios de los varones. 


\section{1. ¿Cuál es la relación entre lo femenino y la ciencia?}

La ciencia ha sido parte inherente de la actividad humana y de las sociedades, pero el conocimiento ha sido un instrumento de poder que otorga ventaja a quienes lo producen. Precisamente el discurso científico ha emanado de fuentes diversas de poder, por lo que es de suma importancia conocer cómo han figurado las mujeres y lo femenino en los discursos científicos.

El quehacer científico se ha caracterizado por asumir visiones epistemológicas sesgadas en donde ha ocurrido doble negación: por un lado se ha negado a las mujeres el derecho a ser sujetos cognoscentes y por otro lado no se ha considerado las experiencias femeninas como válidas, como objetos de conocimiento.

Justamente los estudios de género lo que hacen es criticar y denunciar el Androcentrismo presente en las ciencias. La separación de lo femenino del quehacer de la ciencia tiene un doble resultado: impedir la participación de las mujeres en las comunidades que construyen y legitiman el conocimiento, y expulsar las cualidades consideradas "femeninas" de tal construcción y legitimación, e incluso considerarlas como obstáculos.

Una de las formas de entender esta exclusión y separación es el uso de las metáforas de género que jugaron un papel importante en la formación del conjunto particular de valores, propósitos y metas que la empresa científica representaba. En el siglo XVII, Francis Bacon ${ }^{1}$ en su obra "El nacimiento masculino del tiempo", describía relaciones de género así: "la ciencia anterior representaba solamente un vástago femenino, pasivo, débil, expectante, pero ahora ha nacido un hijo varón, activo, viril, generativo" [...] "Establezcamos un maridaje casto y legal entre Mente y Naturaleza. La Naturaleza va a ser la novia, la que requiere ser dominada, conformada y sometida por la mente del científico" (citado en Flores, 2005, p.70).

Por lo tanto, se asocia a la naturaleza con lo femenino y a la cultura/ciencia con lo masculino, existiendo un orden de superioridad de lo masculino sobre lo femenino. A pesar de esta visión unilateral y limitada, algunas mujeres adelantaban paralelamente sus propios descubrimientos y formulaban teorías frente a la realidad que las circundaba. Ya a finales del siglo XIX, por vez primera en la historia fue posible que una mujer ingresara a los grupos científicos establecidos y, sin embargo, las palabras de Henrietta Bolton escritas en Popular Science Monthly en 1898 no sólo son pertinentes para miles de años de historia sino que siguen siendo ciertas hoy en día: "Como regla general la mujer de ciencia debe ser lo bastante fuerte para valorarse por sí misma, capaz de soportar el sarcasmo y la antipatía a menudo injustas de hombres que sienten celos al ver invadido lo que consideran ser su campo de actividad" (citado en Álvarez, 2008). Ha existido una asociación histórica entre masculino y objetivo, y de manera más específica entre masculino y científico. Justamente la ciencia se ha considerado un campo no emocional y sexualmente neutro.

Evelyn Fox Keller (1991) en "Reflexiones sobre género y ciencia" se pregunta: ¿En qué medida está ligada la naturaleza de la ciencia a la idea de masculinidad, y qué

1 Considerado el Padre del Empirismo, sus pensamientos ejercieron una influencia decisiva en el desarrollo del método científico. 
podría significar que la ciencia fuera de otra forma distinta? La objetividad misma es un ideal que tiene una larga historia de identificación con la masculinidad. Acerca de la masculinidad intrínseca del pensamiento científico, Fox Keller indica que sigue encontrando expresión diaria en el lenguaje y las metáforas que se utilizan para describir la ciencia. Cuando se denominan "duras" a las ciencias objetivas en tanto que opuestas a las ramas del conocimiento más blandas (es decir, más subjetivas). Implícitamente se invoca una metáfora sexual en la que "dura" es masculino y "blanda" es femenino. De forma general, los hechos son "duros", los sentimientos "blandos". Feminización se ha convertido en sinónimo de sentimentalización bajo la lógica siguiente: Una mujer que piensa científica u objetivamente está pensando "como un hombre"; a la inversa, el hombre que siga un razonamiento no racional, no científico, está argumentando "como una mujer".

De estas visiones dicotómicas sobre lo femenino y lo masculino en el ámbito del conocimiento se han generado discursos con poder y control social sobre las mujeres y otros grupos excluidos históricamente. Por poner un ejemplo, ¿quién no conoce la manera en que se ha conceptualizado la sexualidad? Desde la epistemología positivista, por ejemplo, se ha generado un discurso desde el cual se ha tipificado la homosexualidad como enfermedad. De este discurso científico para controlarla surgen las prácticas médicas y psicológicas encaminadas a curar lo que se consideraba una enfermedad.

Justamente los estudios de género lo que hacen es plantear nuevos interrogantes de fenómenos ya conocidos, pero también identifican nuevos problemas que afectan a la humanidad y que no habían sido percibido como tales hasta que una conciencia crítica los tilda como injustos y se interpela a la noción de justicia e igualdad.

En opinión de Marta Lamas (1996) la comprensión del concepto de género se ha vuelto imprescindible, no solo porque se propone explorar uno de los problemas intelectuales y humanos más intrigantes: ¿cuál es la verdadera diferencia entre los cuerpos sexuados y los seres socialmente construidos?, sino porque está también al centro de uno de los debates políticos más trascendentales: el papel de la mujer en la sociedad. Este debate se internacionalizó durante la realización de la IV Conferencia mundial sobre la mujer en Beijing en 1995.

Así también, las desigualdades de género son un tema de debate en distintos escenarios mundiales y locales. Distintos actores sociales han asumido un discurso en pro de la igualdad porque justamente para conocer sobre la calidad de la democracia de un país concreto es necesario preguntarse si los derechos humanos de las mujeres están siendo respetados. Por ello, Naciones Unidas definió -en el año 2000- como uno de los Objetivos del Milenio "Promover la igualdad entre los géneros y la autonomía de la mujer". Estos objetivos contienen indicadores y metas que los Estados parte deben de cumplir para el año 2015.

Se parte del reconocimiento que en ningún lugar del mundo las mujeres tienen el mismo estatus, poder y prestigio que los hombres de su mismo contexto. Por esto existen programas -que desde el paradigma del desarrollo humano- pretenden cerrar las brechas de desigualdad porque está comprobado que en la medida que las mujeres tienen autonomía y poder, sus familias y la sociedad se desarrollan en pro de su bienestar. 
Existe plena conciencia de que ocurren problemas que afectan considerablemente a las mujeres y que son preocupación mundial, por ejemplo: la violencia (en sus diversas expresiones), la pobreza que les afecta, el escaso acceso a los recursos para el desarrollo y al poder político, la trata de personas, la sobrecarga de trabajo, entre otros.

Por ello, los estudios de género desarrollan teorías que critican la manera como se han entendido fenómenos sociales, provocando crisis en la epistemología y en los paradigmas. La introducción de los estudios de género supone una redefinición de todos los temas de variadas disciplinas, sobre todo las relativas a las Ciencias Sociales. Señala Benhabib (1992, p. 38):

Cuando las mujeres entran a formar parte del cuadro, ya sea como objetos de investigación en las Ciencias Sociales, o como investigadoras ellas mismas, se tambalean los paradigmas establecidos, se cuestiona la definición del ámbito de objeto del paradigma de investigación, así como sus unidades de medida, sus métodos de verificación, la supuesta neutralidad de su terminología teórica o las pretensiones de universalidad de sus modelos y metáforas.

La teoría feminista, al aportar una nueva forma de interrogar la realidad, acuña nuevas categorías analíticas con el fin de explicar aspectos de esa realidad que no habían sido tomados en cuenta antes de que se develase el aspecto social de los géneros. Existe un impacto impresionante, tanto en la ampliación del universo conocido como en el desarrollo de los conocimientos, a partir de las herramientas teóricas de género que permiten dar cuenta de hechos hasta entonces desconocidos. En consecuencia, la realidad se tornó más compleja. La visión e interpretación de la realidad se ha transformado. No es lo mismo pensar a las mujeres y a los hombres desde teorías que no reconocen el entramado de los géneros, a reflexionarlos desde teorías elaboradas justamente para dar cuenta de estos fenómenos. Precisamente, estos conocimientos que hoy denominamos de género, han sido el fundamento de numerosas propuestas alternativas históricas, generadas sobre todo a partir de la movilización organizada de mujeres en el mundo.

Rosa Cobo Bedia (2000) plantea que el impacto social y político del movimiento feminista junto a su potencial teórico-crítico, hace posible que el género se convierta en tema obligado de investigación de diversas ciencias.

\section{Ideas conclusivas}

En ningún lugar del mundo las mujeres gozan del mismo estatus, poder y prestigio que los hombres de su mismo contexto. Esta constante es uno de los argumentos utilizados para señalar que la dominación masculina es un hecho histórico, pero proveniente de un orden natural considerado inmutable y hasta necesario para el mantenimiento de las sociedades.

Solo si conocemos la manera en que se reproduce tal sistema de dominación es que podemos transformar la sociedad hacia relaciones entre seres humanos más justas y equitativas. Si conocemos la manera como se estructuran estas relaciones sociales en las más diversas instituciones y los supuestos teóricos que las respaldan, 
podemos entonces cambiar mentalidades e impulsar procesos de cambio social como los que promueve el Feminismo.

El Feminismo es una teoría crítica de la sociedad que produce el conocimiento androcéntrico. Pretende modificar el orden social y producir otro tipo de conocimiento. Es una teoría, pensamiento, práctica social, política y jurídica, que tiene por objetivo hacer evidente y terminar con la situación de opresión de las mujeres, y lograr así una sociedad más justa que reconozca y garantice la igualdad plena y efectiva de todos los seres humanos.

A través de reflexiones como las que plantea este artículo podemos contribuir a desarrollar capacidades para fomentar nuevas relaciones entre los seres humanos y la naturaleza, podemos fomentar la construcción de nuevos arreglos y contratos sociales en donde los seres humanos y su bienestar sean prioridad.

\section{Referencias bibliográficas}

Álvarez, M. (2008). ¿La tecnociencia al servicio de la innovación y la igualdad?. Igualdad en la innovación, innovación para la Igualdad. Vigo: Universidad de Vigo. Recuperado el 27 de marzo de 2014, de http://webs.uvigo.es/xenero/ profesorado/mari_lires/tecnociencia.pdf

Aristóteles (García, C. \& Pérez, G.) (Trads./Eds.). (1981). La Política. Madrid: Editora Nacional.

Benhabib, S. (1992). Una revisión del debate sobre las mujeres y la teoría moral. Isegoría, (6), 37-63.

Breitling, G. (1990). Der verborgene Eros. Francfort: Fischer Taschenbuch Verlag.

Cavana, M. (2000). Diferencia. En C. Amorós (Ed.). 10 palabras clave sobre Mujer. (pp. 85-118). Navarra: Verbo divino.

Cobo Bedia, R. (1995). La democracia moderna y la exclusión de las mujeres. Mientras tanto. (62), pp. 107-119.

Cobo Bedia, R. (2000). Género. En C. Amorós (Ed.). 10 palabras clave sobre mujer. (pp. 55-83). Navarra: Verbo divino.

Durán, M. (1999). Liberación y utopía: La mujer ante la ciencia. Madrid: Akal.

Flores, A. (2005). Reflexiones feministas en ciencia. Cuadernos del CUEG (Centro Universitario de Estudios de Género). Nuevo León: Facultad de Filosofía y Letras, Universidad Autónoma de Nuevo León.

Fox Keller, E. (1991). Reflexiones sobre género y ciencia. Valencia: Ediciones Alfons el Magnánim.

Heller, A. (1983). Aristóteles y el mundo antiguo. Barcelona: Península.

Lagarde, M. (1997). Los cautiverios de las mujeres: madresposas, monjas, putas, presas y locas. México: Colección Postgrado Universidad Nacional Autónoma de México.

Lamas, M. (1996). El género: la construcción cultural de la diferencia sexual. México: Programa Universitario de Estudios de Género, Universidad Nacional Autónoma de México.

Maquieira, V. (2001). Género, diferencia y desigualdad. En E. Beltrán et al. (Ed.). Feminismos: Debates teóricos contemporáneos. (pp. 127-153). Madrid: Alianza editorial. 
Encuentro №. 97, 36-50, 2014

Martín, M. \& Voorhies, B. (1978). La mujer: un enfoque antropológico. Barcelona: Anagrama.

Molina, C. (2000). Ilustración. En C. Amorós (Ed.). 10 palabras clave sobre mujer. (pp. 189-216). Navarra: Verbo divino.

Moreno Sardá, A. (1988). La otra política de Aristóteles: cultura de masas y divulgación del arquetipo viril. Barcelona: Icaria.

Pateman, C. (1996). Críticas Feministas a la dicotomía público/privado. En C. Castells (comp.). Perspectivas feministas en teoría política. (pp. 31-52). Barcelona: Paidós.

Rosaldo, M. (1980). The Use and Abuse of Anthropology: Reflections on Feminism and Cross Cultural Understanding. Signs, (5), 389-417.

Rousseau, J. J. (1980). Del contrato social: Discursos. Madrid: Alianza editorial.

Rubin, G. (1996). El tráfico de mujeres: notas sobre la economía política del sexo.

En M. Lamas (comp.). El Género: la construcción cultural de la diferencia sexual (pp. 35-96). México: Programa Universitario de Estudios de Género.

Sau, V. (2000). Diccionario ideológico feminista, I. Barcelona: Icaria. 